\title{
Thirty-five Years of Legal Abortion: The US Experience
}

\author{
Marlene Gerber Fried
}

\begin{abstract}
1 Introduction
The thirty-fifth anniversary of legal abortion in the US was on 22 January 2008. During these years, millions of women have been able to have the abortions they need, without risk to their lives and health. Yet millions of other women have not. Roe $\mathrm{v}$. Wade, the Supreme Court decision that legalised abortion in the USA, left a gap between legality and access that opponents turned into a chasm filled with legal restrictions, unnecessary and burdensome regulations, continued threats and violent attacks on clinics and providers. Today, abortion is legal, but restricted; stigmatised and continually under attack are the women who are most vulnerable - poor women, women of colour, and young women those who face the greatest obstacles.
\end{abstract}

In this article, I discuss the erosion of abortion rights since legalisation, the political strategies of opponents and advocates and the divisions among abortion rights supporters, in order to demonstrate the need for new vision, strategy and leadership. I come to these issues with a long activist history. I entered the movement in 1977, when the backlash to Roe v. Wade achieved its first big victory in the Hyde Amendment. This legislation prohibited the use of federal funds for abortion, thereby effectively denying the promise of Roe v. Wade to poor women. It also crystallised the race and class dynamics within the abortion rights movement. Ignoring the fact that access to abortion, not simply its legality, was of central concern for women of colour, and for all poor women, the prochoice movement failed to make the restoration of public funding for abortion a priority. Instead, it focused on defending Roe v. Wade.

Although I am critical of this political approach, as well as other aspects of the pro-choice movement, I am also unwaveringly committed to the importance of fighting for abortion rights as part of a broader struggle for women's ability to control their lives. Our battle in the USA is ongoing. We have lost ground on abortion and face new challenges. For example, our opposition has shifted its approach, talking more about protecting women than defending fetuses. Claims that abortion is violence against women and attempts to establish links between abortion, mental illness and breast cancer are all part of this strategy, designed to undercut the claim that the anti-abortion movement does not care about women. The anti-abortion movement continues to be a formidable foe. There are no signs that this will change in the foreseeable future.

In the face of losses and ongoing threats, abortion rights advocates are taking a critical look at their own strategies and politics. I will argue that the reproductive justice approach, currently being promoted by women of colour organisations and their allies, offers the best possibility for restoring what has been lost, meeting new attacks, and for gaining the full array of reproductive freedoms we have never had. In contrast to the narrow choice agenda, reproductive justice is expansive, locating abortion rights in the context of human rights and social justice. As such, it is the most dynamic and inclusive vision for moving us forward.

While this article focuses on the USA, the policy implications and associated harms of US policy are experienced throughout the world. Through actions that include re-imposing the Global Gag Rule, ${ }^{1}$ diverting US\$34 million from UNFPA to abstinenceonly programmes in the USA, and pushing antiabortion agenda at all international meetings on women's health and rights, anti-abortion politics in the USA in fact undermines access to reproductive health services for millions of women worldwide. 


\section{Abortion access in the USA}

While Roe v. Wade was a tremendous victory for women's health and lives, it was only a first step towards gaining abortion rights for all women. ${ }^{2}$ Access remained the unfinished agenda. The attacks began as soon as abortion became legal. Roe v. Wade galvanised the anti-abortion movement: in the year after the decision was handed down, hundreds of bills were proposed to limit abortion. The movement received a major boost in the 1980s when the presidency of Ronald Reagan moved the Conservative Right, which had been on the margins of US politics, into a position of power. Opposition to abortion and gay rights became the focal points of the Rights' anti-woman and anti-sexuality agenda. The anti-abortion movement began to chip away at the legal right by attacking access. They were highly visible, well funded and had evangelical and Catholic churches as their base. Ronald Reagan had been elected president with strong support from antiabortion and other conservative organisations. In turn, his administration gave them unprecedented access to political power and resources. Federal monies were channelled to anti-abortion counselling centres and religious organisations to teach abstinence-only sexual education. Illegal action in the form of attacks on abortion and family planning clinics also intensified during this period.

Since that time, abortion opponents have followed a dual strategy. First, to achieve their long-range goal of making abortion illegal, they support legislative efforts at the state and federal levels that weaken Roe v. Wade and could eventually be used to overturn it. This is within their reach. Only one more vote on the Supreme Court is needed, and judicial appointments are one of the high stakes in presidential elections. Second, in the short run, as we shall see, they work to erode access. The two strategies reinforce each other. Campaigns for bans and restrictions build support for further restrictions and for the idea that women should not be able to make their own decisions about terminating a pregnancy. Even failed battles cast abortion in negative terms, reinforcing the stigma and shame associated with it: for example, all of the efforts to restrict public funding for abortion centre on the claim that citizens should not have to pay taxes for an act they consider morally wrong, thus fuelling the notion that abortion is wrong and that women who have them are immoral. Other campaigns spread misinformation: for example, attempts to restrict minors' access to abortion by introducing state-level parental consent or notification laws often leave young women with the impression that abortion is not legal for them.

During the 35 years since Roe v. Wade, attacks on abortion access - legal, illegal and sometimes violent - have been persistent. Since 1994, seven people involved in abortion care have been murdered; there have been 17 attempted murders, 41 bombings, 175 arsons, and thousands of incidents of picketing and threats against clinics that offer reproductive health services (Saporta 2008). There has also been a steady barrage of restrictive legislation - bans on government funding and abortion procedures, lawsuits and governmental policies that have significantly decreased abortion access. The case of 'Sarah', below, reflects the multiple erosions:

'Sarah' is a 31-year-old mother who works full time, earning $\$ 1,000$ a month with no health insurance. When she was 15 weeks pregnant, she was unable to get an abortion in her home state of Alaska, where there are only three abortion providers and none who perform abortions after 14 weeks. She had to use her rent money to fly to another state hundreds of miles away to get one. (National Network of Abortion Funds 2005)

'Sarah' was one of the fortunate women who, with financial assistance from grassroots abortion funds and a friend who gave her a place to stay, was able to overcome the barriers to securing a safe abortion. Each year in the USA, there are thousands of 'Sarahs' - women of all ages, religions, races and ethnicities, women in prison, in the military, women who are single and married, who must try to overcome multiple barriers in order to obtain an abortion. Too many do not succeed. The prohibitions on funding abortion ${ }^{3}$ stand as the major economic impediments. Thirty-three out of 50 states follow the federal government's lead and also refuse to pay for abortions. Even in the 17 states that have abortion funding, unrealistically strict eligibility criteria exclude many women who are, nonetheless, too poor to afford an abortion. Although abortion rates are dropping overall, they continue to rise for poor and low-income women (Jones et al. 2002) who, like 'Sarah', must use money they need for other necessities to pay for their abortions, or have babies they cannot afford. 
Other restrictive laws and policies also directly curtail access and have had a long-term effect on the availability of abortion services. The number of abortion providers has steadily declined. This has been attributed to many interrelated issues: the attacks on providers, the stigma associated with abortion, the high cost of liability insurance coupled with unnecessary and costly regulations on clinics, and the lack of training in medical schools. As a result, 87 per cent of counties in the USA have no abortion provider, and 35 per cent of women live in those counties (Guttmacher Institute 2008). Young women face the additional barrier of laws requiring parental consent or notification in order to have an abortion. ${ }^{4}$ When combined with other restrictions, such as laws mandating that a woman wait a certain period of time between counselling and having her abortion, bans on so-called 'partial birth' abortions, and decreasing hospital-based services, ${ }^{5}$ a safe and legal abortion can become virtually impossible to obtain.

For the past eight years, anti-abortion policies have been in the forefront of President Bush's agenda. He has filled high level cabinet and agency positions, federal judgeships and the Supreme Court with people who oppose abortion and contraception. Bush signed the Federal Abortion Ban, which President Clinton had vetoed, and which had already been declared unconstitutional by the Supreme Court. His persistence paid off. Despite strong legal precedent, in 2007, the newly configured court declared the ban constitutional. ${ }^{6}$

The assault on abortion is part of a much broader effort to reverse the gains made by the women's, civil rights and welfare rights movements of the 1960s and 1970s. While the attacks have tended to escalate during the periods when Republicans have been in control of the presidency and Congress, they have been continuous since abortion was legalised. As a result, abortion and other reproductive rights have been seriously compromised in the USA, especially for the most vulnerable women, while the negative effects of US international policy on reproductive rights have been felt in many parts of the world

\section{Resisting the anti-abortion movement}

Abortion rights forces were not prepared for the allout assault following legalisation. The movement that did re-emerge in the late 1970s was shaped in response to the multi-faceted attack on abortion rights. While the earlier organising to make abortion legal had placed it in the context of the broader struggle for women's liberation, organisations that emerged after Roe v. Wade narrowed their focus, making the legal right to abortion their sole priority The language and ideology of choice and privacy replaced women's rights and even abortion rights. This approach was adopted in the hope that it would have wider appeal and expand the base of support for legal abortion, encompassing even those who were conservative on issues of social and economic welfare. Although temporarily successful insofar as it split the Right, it was also a highly problematic strategy.

Making abortion rights a matter of individual choice and privacy marginalised issues of access, where they remained until the 1990s when Clinton's election to the presidency provided a temporary respite from the threat of overturning Roe v. Wade. During this period new organisations were created that focused on different aspects of access: training more doctors; expanding the provider pool to include advanced practice clinicians; marshalling support for existing providers; directly funding abortions for low-income women and girls; advocating to reinstate public funding and providing counselling and support for women who have had abortions. Other strategies were directed towards broadening the agenda and making alliances with new constituencies, including communities of colour, the LBGTQ (lesbian, bisexual, gay, transgender, queer) movement and youth (Gerber Fried and Clarke 2000).

This organising has led to important gains. For example, together the grassroots members of the National Network of Abortion Funds, where my activism has been located, raised US\$2.6 million in 2007 and provided direct financial assistance to 23,000 women. Medical Students for Choice has 10,000 members and chapters at 123 medical schools. It has successfully expanded training opportunities. Through the ongoing efforts of other organisations, today many family practice doctors are providing medical abortions. However, the overall trend has not been reversed - access continues to decline, support for restrictions on abortion grows, especially among younger women, and abortion rights supporters are caught in the defensive mode, reduced to fighting in a piecemeal way to hold whatever ground we can. We need a more profound political shift both in terms of power, but also in terms of vision and strategies. 


\section{From choice to justice}

For decades, there has been frustration over the choice framework and single-issue abortion politics. Women of colour have been in the forefront of the critique, arguing that the narrow choice agenda reflects neither the diversity of women's reproductive experiences nor the range of issues that comprise reproductive freedom. Underlying their objections is the understanding that women's reproductive lives are, in large part, determined by their race and class. In the capitalist context of the USA, the idea of choice invokes the marketplace things that are for sale can be chosen. This neoliberal notion locates rights within an individual and obscures the social context and conditions required to exercise rights (Silliman and Bhatcharjee 2002). However, this analysis is incorrect. Individual decisions cannot be implemented without social supports such as housing, healthcare, and welfare benefits, all of which have been eroded by the Right. 'Choice' does not speak to women who must struggle to meet their basic survival needs. For these women, all too often, both motherhood and abortion are out of reach. Casting abortion as a matter of choice only reinforces the disparity between the predominantly white and middle-class women who were seen as the champions of abortion rights, and the lowincome women and women of colour worldwide who bear the brunt of restrictions.

Choice has also been used to silence concerns about women's health and potential coercion in the area of new reproductive technologies, including contraception. For example, Norplant was the first new contraceptive to be introduced into the USA in 25 years. It was met with relatively uncritical approval by mainstream women's groups, who saw it as expanding women's contraceptive options. At the same time, it immediately became a tool of coercion when a judge made acceptance of Norplant a condition of probation for a woman convicted of child abuse (Roberts 1997). Depo-Provera too has been seen as providing women with greater choice, and it has been difficult for women's health advocates to raise concerns about these contraceptive methods without being accused of playing into the hands of opponents of abortion and contraception.

The narrowly framed choice agenda has perpetuated racial and class divisions in the movement, weakening the ability to resist the threats and to move forward to secure rights never achieved. Today, advocates from diverse political perspectives agree that 'choice' should be abandoned. However, there is no agreement on what should replace it. Some of the more popular new framings are themselves problematic. They seem to abandon abortion. Many political leaders and advocacy organisations, including current presidential candidate Barack Obama, are trying to rally support for the 'Putting Prevention First Act', arguing that unintended pregnancy and abortion can be eliminated by increasing access to contraception. In arguing for prevention, some supporters of abortion rights, including current presidential candidate Hillary Clinton, talk about abortion as 'a sad and tragic choice' and the need to make abortion 'safe, legal and rare' (Saletan 2005). Portrayed in this way, abortion is a 'necessary evil'. However inadvertent, these messages reinforce the negativity of abortion and provide grist for the opposition. They also miss the fact that for many women, abortion is a life-saver and that the real tragedy is forcing a woman to have a child against her will. Of course greater contraceptive access is desirable. It will not however replace the need for access to safe, legal abortion as a backup to the use of contraception, and as one of the tools available to women trying to control their reproductive lives (Hartmann 2006). So long as women get pregnant when they do not want to be, abortion must be part of a woman's reproductive safety net.

Women of colour have long argued that 'choice' does not capture their reproductive experiences. Historically, they have organised for reproductive and sexual rights outside of the choice framework. They created their own organisations and coalitions, and redefined reproductive rights to emphasise the needs of their communities. Overarching socioeconomic inequalities and racism shape these communities and the lives of women in them. They have disproportionate rates of poverty, lack of access to healthcare services and information, high incidences of violence, and poorer health outcomes in all areas. Examples include the fact that a majority of new HIV cases in the USA are among AfricanAmerican and Latina women; native women experience very high rates of reproductive tract infections; Latina women have proportionately high rates of cervical cancer; Asian-American women are the only group to experience a rise in overall cancer mortality. Consequently, women from these communities are developing the analysis and agenda of reproductive justice, as a means to focus on 
achieving the broad set of conditions necessary for reproductive and sexual freedom. Asian Communities for Reproductive Justice (ACRJ), a founding member of the SisterSong Women of Color Reproductive Health Collective, has been a leader in this process. In their words, 'Reproductive justice exists when all people have the economic, social and political power and resources to make healthy decisions about our gender, bodies and sexuality for ourselves, our families and our communities' (Asian Communities for Reproductive Justice 2005). Achieving this goal requires change at all levels and an end to all forms of oppression, 'including forces that deprive us of self-determination and control over our bodies, and limit our reproductive choices. This oppression has been implemented through the controlling and exploiting of women and girls through our bodies, sexuality, and reproduction (both biological and social) by families, communities and institutions' (Asian Communities for Reproductive Justice 2005).

The concept of reproductive justice provides an expansive understanding of reproductive freedom, integrating the race, class, gender and cultural dimensions of women's lives. It also helps to overcome another historic feminist divide, the failure to disassociate abortion rights from population control policies. By not providing the necessary supports for mothering, and through policies that actively undermine the ability of low-income women to take care of their children, ${ }^{7}$ population control policies devalue reproduction by women of colour. The lack of government-subsidised childcare, in addition to restrictive welfare policies, such as those requiring women to work outside the home even if they have young children, make it difficult for lowincome women of colour in the USA to support their families. Such policies also send a clear message that they are not supposed to have children. ${ }^{8}$

Finally, reproductive justice politics places abortion where it belongs - as part of women's lives, human rights and social justice. Abortion is neither the centre of reproductive freedom, nor out of the picture. Abortion rights are part of a holistic understanding of women's needs. By linking issues in this way, the concept of reproductive justice has the potential to draw new constituencies to the struggle for reproductive freedom.

\section{Conclusion}

The 2008 presidential election presents an opportunity for significant positive change in national leadership. At the same time, as we have seen, the politics of abortion transcends party lines. Electing Democrats is not adequate to securing abortion rights, let alone a full reproductive justice agenda. I believe that building the reproductive justice movement ${ }^{9}$ is the best hope for restoring what has been lost, meeting new attacks, and gaining the full array of reproductive freedoms we never had. It is the most dynamic and inclusive vision for moving us forward. Because it is connected to other health, human rights and social justice movements, this broad and inclusive vision of reproductive freedom provides an opportunity to bring new allies to the abortion rights struggle. I therefore hope that reproductive justice will become the central frame for reproductive rights organising in the USA, because it is right and the only way to win.

\section{Notes}

1 The Global Gag Rule (officially termed the Mexico City Policy) was reinstated by President George $W$. Bush on his first day in office in January 2001. It mandates that no US family planning assistance can be provided to foreign NGOs that use funding from any source to: perform abortions in cases other than a threat to the woman's life, or in cases of rape or incest; provide counselling and referral for abortion; or lobby to make abortion legal or more available in their countries. The Gag Rule applies even in countries where abortion is already legal. For information about the Gag Rule's impact, see www.globalgagrule.org/impacts.htm

2 Abortion was illegal throughout the USA for approximately 100 years - from the middle of the nineteenth century until Roe v. Wade. Only a few states liberalised their abortion laws, and even these reforms only took place in the few years preceding Roe. During this time, the number of illegal abortions is estimated at 1.2-2 million annually. The number of deaths is harder to verify, with estimates ranging from 200-5,000 annually, of overwhelmingly poor women and women of colour. Further, several hundred thousand women a year were hospitalised with severe complications from illegal abortions. During the period of illegality, there were abortion providers. Some, like the feminist Jane Collective in 
Chicago, doctors, and other medical personnel, risked their own livelihoods to deliver safe, effective and supportive care. Unfortunately, the back alley butchers did not hold themselves to the same standards of care. Which type of abortion you could obtain most often depended on your race, class and where you lived. Legalising abortion did not guarantee that every woman would be able to get an abortion when she wanted to. However, it did bring safer and more affordable services to more women.

3 Until 1994, the only exception was a threat to the life of the pregnant woman. In 1994, the law was changed to include exceptions for rape and incest.

4 Thirty-five states currently enforce parental consent or notification laws for minors seeking an abortion. The Supreme Court ruled that minors must have an alternative to parental involvement, such as the ability to seek a court order authorising the procedure.

5 Hospital-based services have also steadily declined, a trend exacerbated by the trend of public hospitals and insurance plans that being merged with those that are religiously affiliated. Birth control, sterilisation, abortion, infertility services and counselling for HIV/AIDS and other STIs may be banned by hospitals following religiously based health restrictions. For more information, see www.mergerwatch.org

6 On 18 April 2007, the Supreme Court handed down its decision to uphold the Federal Abortion Ban (also known as the 'Partial Birth Abortion Act of 2003') in Gonzales v. Carhart and Gonzales v. Planned Parenthood, disregarding its own precedent, as well as the decisions of three federal and three appellate courts, all of which had found that the law was unconstitutional

\section{References}

Asian Communities for Reproductive Justice (2005) A New Vision for Advancing our Movement for Reproductive Health, Reproductive Rights and Reproductive Justice, www.reproductivejustice.org/ download/ACRJ_A_New_Vision.pdf (accessed 23 May 2008)

Gerber Fried, M. and Clarke, S. (2000) 'Expanding Abortion Access: The U.S. Experience', in B. Klugman and D. Budlender (eds), Advocating for Abortion Access: Eleven Country Studies, The Women's Health Project, School of Public Health, Johannesburg: Witwatersrand University Press because it failed to include an exception to protect women's health.

7 Welfare Reform in the USA, passed by the Clinton administration in 1995, is another form of eugenics, since it prohibits increases in payments to poor families even if they have more children.

8 In a related but more directly punitive approach, state and local governments have increasingly used fetal rights to criminalise pregnant women. Over 200 women have been prosecuted for drug use during pregnancy and for other behaviours that allegedly threaten the health of the fetus. These prosecutions disproportionately affect low-income women of colour who are more likely to receive healthcare in urban, public hospitals, where they are subject to state scrutiny and interference. The majority of women charged with 'prenatal crimes' are poor and African-American. The threat of prosecution keeps women from seeking prenatal care, medical care during delivery, and follow-up care. This results in an increased number of unhealthy babies and women. Public health and women's advocates point out that if the goal were to promote and protect the health of women and children, the approach would be very different: drug treatment rather than jail time would be offered. As it stands, there are few treatment options available to pregnant women, and in many locales, none whatsoever.

9 For more on Reproductive Justice, see Loretta Ross 'Understanding Reproductive Justice', in Political Environments, Spring/Summer 2007; www.sistersong.net, 'A New Vision for Reproductive Justice', www.reproductivejustice.org (Asian Communities for Reproductive Justice); and www.emerj.org (Expanding the Movement for Reproductive Justice).

Guttmacher Institute (2008) Facts on Induced Abortion in the United States, www.guttmacher.org/pubs/ fb_induced_abortion.html (accessed 1 August 2008) Hartmann, Betsy (2006) Abortion and the Politics of Prevention, www.zmag.org/sustainers/content/ 2006-11/07/hartmann. cfm (accessed 1 August 2008) Jones, Rachel; Darroch, Jacqueline and Henshaw, Stanley (2002) 'Patterns in the Socioeconomic Characteristics of Women Obtaining Abortions in 2000-2001', Perspectives in Sexual and Reproductive Health 34.5: 226-34, 229, 231

National Network of Abortion Funds (2005) Abortion Funding: A Matter of Justice: 15, 
www.nnaf.org/policy_report.html (accessed 1 August 2008)

Roberts, Dorothy (1997) Killing the Black Body: Race, Reproduction and the Meaning of Liberty, New York: Vintage Books: 151-2

Saletan, William (2005) Safe, Legal, and Never: Hillary Clinton's Anti-abortion Strategy, http://slate.msn.com/id/2112712
Saporta, Vicki (2008) Observing Provider Appreciation Day, National Abortion Federation, 10 March 2008, www.rhrealitycheck.org/node/6749 (accessed 29 March 2008)

Silliman, Jael and Bhatcharjee, Anannya (2002) Policing the National Body: Race, Gender and Criminalization, Boston: South End Press: xi 